\title{
КОМПЛЕКСНИЙ ПІДХІД ДО РОЗВ'ЯЗАННЯ ЗАДАЧІ ВИБОРУ ЗАСОБІВ УПОРЯДКУВАННЯ СЕРЕДОВИЩА У ГНУЧКИХ КОМП'ЮТЕРНО-ІНТЕГРОВАНИХ СИСТЕМАХ
}

\author{
Анотація: Анотація: Описані переваги комплексного підходу при виборі \\ складу системи упорядкування середовища, що дозволяє підвищити ефектив- \\ ність вибору за рахунок врахування всіх особливостей об'єктів виробництва, \\ засобів упорядкування, технологічного процесу та взаємозв'язків між ними і \\ емпіричного досвіду щодо синтезу системи упорядкування середовища. \\ Ключові слова: Ключові слова: засоби упорядкування середовища, нейро- \\ фаззі моделі, гнучкі виробничі системи
}

\section{І. Вступ}

В сучасних умовах ефективне економічне використання таких складних та дорогих систем як ГКІС потребують відповідної організації виробництва, направленої на максимізацію коефіцієнта завантаження обробляючих ресурсів, забезпечення безперебійної роботи технологічного обладнання та оперативного реагування на нештатні ситуації, задоволення зростаючих вимог щодо забезпечення гнучкості виробничих систем. Невід'ємною складовою такої організації виробництва є проблема упорядкованості технологічного середовища, що є особливо важливою в умовах дрібносерійного та індивідуального гнучкого виробництва, що реалізується в умовах неупорядкованого чи слабко упорядкованого середовища і частого переналагодження основних обробляючих ресурсів. Тому задача синтезу ефективної системи упорядкування середовища (СУС) залишається однією з найбільш важливих в рамках максимізації загальної ефективності роботи ГКІС. Першочерговою складовою цієї задачі є вибір засобів упорядкування середовища (ЗУС), що вимагає узгодження їх функціональних можливостей та технічних характеристик з вимогами технологічного процесу та особливостями об'єктів виробництва (OB). Очевидно, що за відсутності прямої відповідності між властивостями класів та окремих ОВ і ЗУС, враховуючи багатоваріантність вибору, велику розмірність та наявність невизначеностей вибору, вимоги гнучкості та синхронізації підсистем на різних рівнях ієрархї, просторову розподіленість - задача вибору складових СУС є складною і слабкоформалізованою. I незважаючи на значний накопичений досвід, переважна більшість робіт присвячених питанням вибору ЗУС є спеціалізованими, орієнтовані на окремі класи ЗУС чи ОВ та не враховують комплексні вимоги, що висуваються до СУС. Це в свою чергу

(c) В.В. Олійник, 2014 
ускладнює можливості створення автоматизованих методик та засобів вибору складу СУС.

Тому доцільним є розробка комплексного підходу до розв'язання задачі вибору раціонального складу СУС, що дозволить підвищить ефективність вибору за рахунок врахування всіх особливостей ОВ, ЗУС та ТП та взаємозв'язків між ними, в т.ч. нечітких, та емпіричного досвіду щодо синтезу СУС.

\section{II. Структура задачі вибору раціонального складу СУС}

На основі структурно-фрунціонального аналізу процесу упорядкування та СУС можна представити останню в узагальненій моделі ГКІС фрункцією

$$
\Phi_{\text {СУC }} \in M \times \Phi \times U \times T \times K
$$

де $M$ відповідає моделі ОВ, $\Phi$ - метод упорядкування (що може бути узагальнено представлений функціями упорядкування $\Phi_{y} \rightarrow\left\{\Phi_{O}, \Phi_{T P}, \Phi_{\Pi}, \Phi_{H}\right\}$, де $\Phi_{O}-$ фрункція орієнтування; $\Phi_{T P}-$ фрункція транспортування; $\Phi_{\Pi}-$ фрункція подавання; $\Phi_{H}$ - функція нагромадження), $U$ - засоби упорядкування середовища та їх класи (разом з функцією упорядкування $\Phi$ визначає фрункціональне узгодження ЗУС та ОВ $R=\Phi \times U), T$ - часові та кількісні особливості технологічних процесів, $K$ - просторова структура СУС та орієнтуючих і транспортуючих рухів. Таке подання відображає, з одного боку, часову та просторову розподіленість системи, а з іншого - багатоваріантність засобів реалізації як функціональних та технологічних операцій, так і власне структур СУС.

Тоді вибір раціонального складу СУС може бути представлено процедурою прийняття рішень $Z$, що відповідає співставленню множин конструктивних і фізико-технічних особливостей ОВ та функціональних можливостей ЗУС з урахуванням множини параметрів вимог-обмежень технологічного процесу $T$, з наступним вибором із одержаної множини функціонально-узгоджених ЗУС субоптимального складу СУС шляхом застосування відповідних критеріїв, тобто $Z$ :

$$
C \subseteq O_{i} \times\left\{\Phi_{O} \vee \Phi_{T P} \vee \Phi_{\Pi} \vee \Phi_{H}\right\} \times U \times T,
$$

де $O_{i}-i$-й ОВ, $C$ - множина функціонально-узгоджених варіантів складу СУС: $C=\left\{C_{n} \mid n=\overline{1, N}\right\}, n$ - номер варіанта складу СУС; $N$ кількість варіантів складу СУС (рис. 1).

Комплексний підхід до задачі вибору складу СУС вимагає врахування всіх суттєвих взаємозв'язків моделі $\Phi_{C у C}$ з оглядом на особливості окремих компонентів. На практиці цьому відповідає фрунціонально-технологічне узгодження наборів ЗУС, що включають традиційні: улову обслуговуваності (функціональне узгодже- 


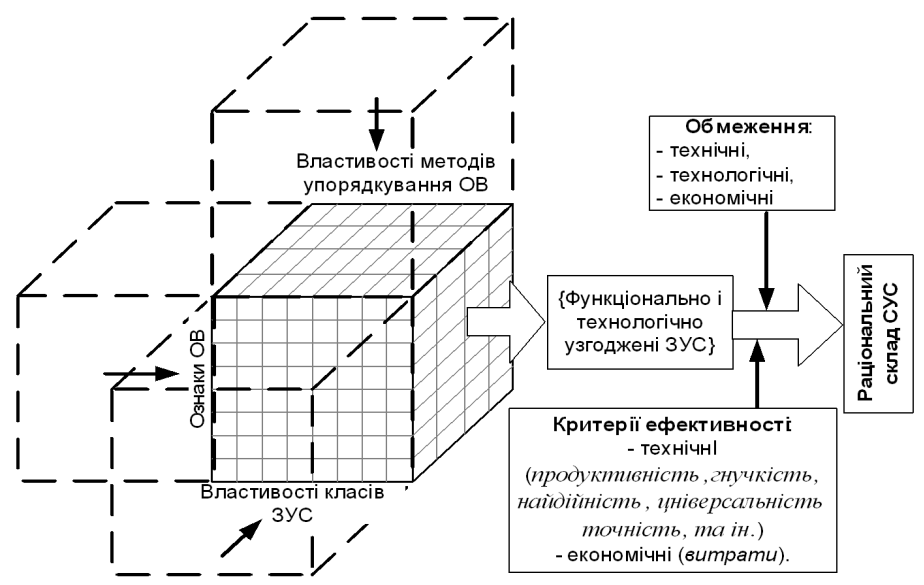

Рис. 1 - Графічна інтерпретація комплексного підходу до вибору раціонального складу СУС

ння ОВ і ЗУС), улову технологічності ЗУС (технологічне узгодженняЗУС), улову технологічності $O B$ (технологічне узгодження ОВ та ТП), які зазвичай перевіряються окремо. При цьому успішний розв'язок задачі вибору раціонального складу СУС вимагає комплексного врахування всіх трьох умов, наявних обмежень і вимог максимізації ефективності системи за різними критеріями. При цьому загальна задача не може бути представлена розв'язками окремих підзадач, оскільки задоволення кожної з умов окремо не гарантуе досягнення загальної мети i, тим більше, ефективності рішення.

\section{III. Реалізація функціонально-технологічного узгодження ОВ та ЗУС.}

Таким чином функціонально-технологічне узгодження ОВ і наборів ЗУС е основним та найскладнішим етапом вибору раціонального складу СУС, характеризуеться багатофакторністю і багатоваріантністю розв'язків, складністю, слабкою формалізованістю та не повною визначеністю зв'язків між компонентами, нечіткостями в поданні характеристик (як об'ективними - при неможливості чіткого визначення так і суб'ективними - навмисне введення нечіткості для зменшення кількості значень ознак та встановлення взаемозв'язків між компонентами). Так можна виділити значний вплив нечіткого характеру інформації про ОВ, що е наслід- 
ком лінгвістичного подання ряду характеристик OB, експертного оцінювання параметрів ОВ технологом, результатом автоматичної ідентифікації та впливу зовнішніх факторів, зокрема, технічного характеру (запиленість, замасленість, якість поверхні ОВ) тощо [1].

Методологічною основою функціонально-технологічного узгодження ОВ і ЗУС є їх універсальні класифікатори. Аналіз відомих інформаційних джерел дає підстави зробити висновок, що для використання в комплексному підході існуючі класифрікатори потребують доопрацювання з метою врахування взаємозв'язків та узгодження властивостей ОВ, ЗУС та ТП, з одного боку, і врахування можливої нечіткості та невизначеностей цих взаємозв'язків, з іншого.

Як зазначалося вище, для уніфікації опису модель $M_{A}$ OВ доцільно вважати нечіткою [1]. Цього вимагає наявність лінгвістичних невизначеностей в описах таких параметрів ОВ як форма, співвідношення розмірів, найбільший габаритний розмір, та можливість виникнення нечіткості на невизначеності в інших класифікаційних ознаках ОВ в залежності від джерела інформації(експерт, засоби автоматичної ідентифікації, непрямі вимірювання). За результатами проведеного аналізу і систематизації функціональних можливостей ЗУС сформована формальна модель ЗУС:

$$
M_{B}=(B, K, Y, \gamma, u),
$$

де $B=\left\{b_{r}\right\}, r=\overline{1, R}$ набір класів ЗУС, $K=\left\{k_{s}\right\}, s=\overline{1, S}$ - множина конструктивно-технологічних обмежень, які накладаються різними класами обслуговуючих пристроїв на ОВ, що можуть обслуговуватись; $Y=\left\{y_{l}\right\}, l=\overline{1, L}$ - множина технологічних параметрів, які характеризують класи ЗУС; $\gamma: B \rightarrow K$ ставить у відповідність кожному класу ЗУС конструктивно-технологічні обмеження, що він накладає на OB; $u: B \rightarrow Y$ визначає технологічні параметри різних класів ЗУС.

Засобом встановлення відповідності між класами ЗУС та їх технологічними параметрами і конструктивно-технологічними обмеженнями, що накладаються на OB, є відповідний фрункціональнотехнологічний класифрікатор, що може включати наступні класифрікаційні ознаки: функціональні можливості, види орієнтуючих рухів, вид силового впливу, тип конструкції, спосіб конструктивної реалізації, ступінь універсальності, дискретність, вид керування.

Така модель $M_{b}$ вже містить засоби забезпечення технологічного узгодження ЗУС. Оскільки задача оцінки технологічності ОВ при проектуванні структури СУС зводиться до простого накладання додаткових обмежень $G$, функціонально-технологічне узгодження ОВ і ЗУС зводиться до реалізації відображення $\beta: A \times B \rightarrow B^{\prime}$, де $B^{\prime}$ - підмножина ЗУС, здатних до обслуговування елементів множини ОВ. 


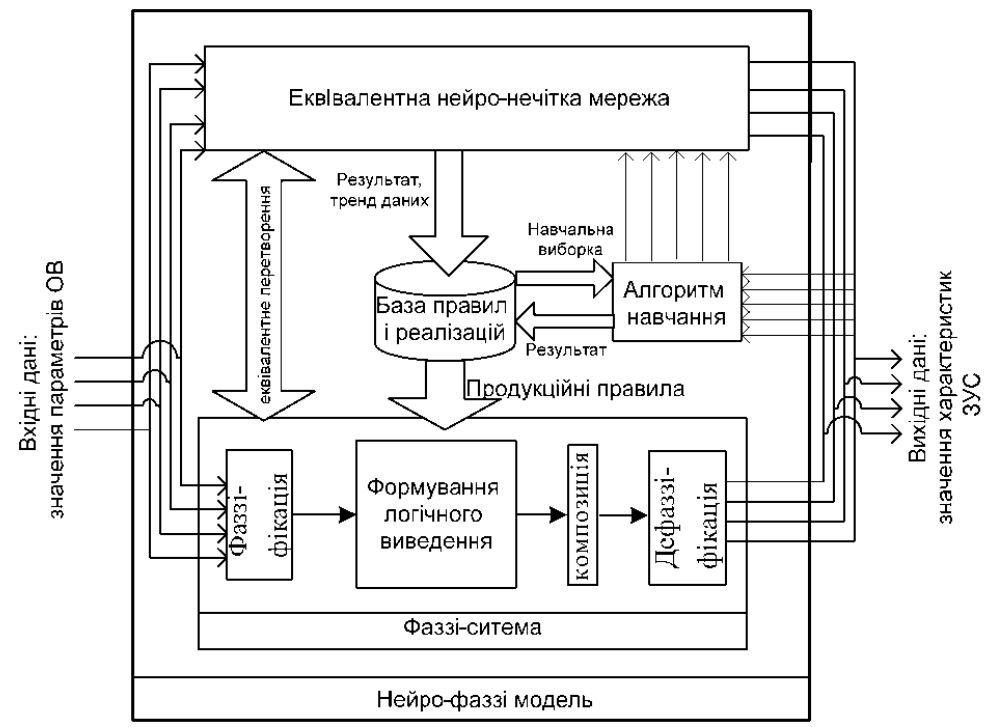

Рис. 2 - Узагальнена структура НФМ узгодження параметрів ОВ та ЗУС

Враховуючи нечіткість моделі ОВ $M_{A}$ та описані вище особливості функціонально-технологічного узгодження ОВ і ЗУС відображення $\beta$ є нечітким [1], а для його інтерпретації слід вибрати відповідну технологію штучного інтелекту.

Для реалізації узгодження множин параметрів ОВ і ЗУС (відображення $\beta$ ) доцільним $є$ використання нейро-фаззі моделі (НФМ) подання та прийняття рішень як основи процесу формування допустимих наборів ЗУС і автоматизованого вибору складу СУС в цілому. Застосування нейро-фаззі підходу в порівнянні з альтернативними підходами дозволяе поєднати переваги мережевих і нечіткологічних технологій: використати нечітке подання інформації про властивості ОВ, можливості логічного виведення на основі знань та емпіричних закономірностей у вигляді правил продукцій про взаємозв'язки між ОВ, ЗУС і ТП, здатність до інтерпретації результатів вибору, логічна прозорість, адаптивність, можливість навчання та автоматизованої екстракція знань з масивів експериментальних даних.

Технічно НФМ реалізуеться нейро-нечіткою мережею (принцип роботи описано в [3]),та еквівалентним нечітким контролером (рис. 2).

Використання такої НФМ дозволяе підвищити якість рішень за рахунок врахування лінгвістичних невизначеностей та викори- 
стання адаптивних можливостей моделі. Автором проведено експериментальне дослідження такої НФМ [2] та доведена їі більша ефективність в порівнянні зі звичайними нейромережевими моделями. За результатами проведених досліджень сформульовані рекомендації щодо достатності кількості правил і об'єму навчальної вибірки, рівнів значущості виходів та інших практичних аспектів використання НФМ. Дослідження показали, що переваги НФМ проявляються тим більше, чим більша нечіткість і лінгвістична невизначеність моделі та вхідних параметрів, що дозволяє рекомендувати застосування нейро-фраззі підходу в інших задача синтезу/аналізу ГКІС, де проявляються наведені властивості.

\section{IV. Узагальнена методика вибору раціонального складу СУС}

На підставі розглянутих особливостей процесу вибору ЗУС і інтелектуальних засобів його імплементації для реалізації комплексного підходу для вибору раціонального складу СУС можна запропонувати наступну узагальнену методику, що є процедурою $Z$ прийняття рішень (рис. 3):

I. Eman Z1 функціонального і технологічного узгодження ЗУС, OB і ТП: $C_{n} \rightarrow C_{\text {узг }}$, що реалізується синтезованою НФМ. Вихід НФМ являє собою набір рівнів значущості термів всіх вихідних характеристик ЗУС. Встановлення відповідності $\chi$ отриманих значень характеристик типовим ЗУС може виконуватись або на цьому етапі, або після 2-го етапу, залежно від виду обмежень. Відношення $\chi$ залежно від особливостей задачі може реалізовуватись методами максимальної або припустимої значущості. Функціональне

відображення $v$ реалізуе перевірку на непорожність отриманої множини, що забезпечує можливість алгоритмізації та програмної реалізації методики. II. Eman Z2 накладання на множину функціонально і технологічно узгоджених наборів ЗУС наявної множини $G$ технічних, технологічних, економічних та організаційних вимог-обмежень: $C_{y з} \rightarrow C_{\text {доn }}$. Накладання обмежень $G$ без втрати узагальнення може бути зведено до обнулення рівнів значущості відповідних термів ознак, що обмежуються (у випадку використання рівнів значущості).

III. Eman Z3 технічної і економічної оцінки допустимих варіантів складу СУС - визначення ефективного за заданими критеріями варіанту складу СУС з множини допустимих: $C_{\partial о n} \rightarrow C_{e ф}$.

Виділення раціонального набору ЗУС з множини допустимих реалізуеться на основі оцінки їх ефективності за допомогою заданих критеріїв і у загальному випадку може бути виражено перетворенням $\varphi: B^{\prime} \rightarrow B$ ", де $B$ " - множина ЗУС, що відповідає раціональному складу СУС. Комплексний підхід має передбачати можливість введення додаткових критеріїв якості та автоматичне оцінювання альтернативних наборів ЗУС у рамках загальної методики. 


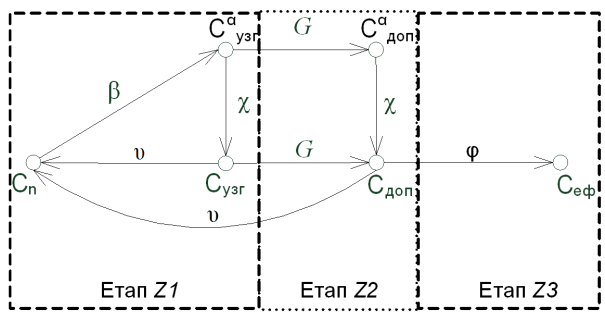

Рис. 3 - Графічне подання методики вибору ЗУС у вигляді орієнтованого графра

Критерії належать до 2 груп: технічні $K_{m}=\left\{k_{i}\right\}, i=\overline{1, M}$ (циклова продуктивність, ступінь технологічної універсальності, технологічна гнучкість, надійність, точність оріентування) та економічні $K_{e}=\left\{k_{j}\right\}, j=\overline{1, N}$ (одноразові та періодичні витрати), а також методика їх врахування для розрахунку узагальненого показника ефективності варіанту складу СУС на основі зваженого критерію:

$$
\operatorname{opt} K(x)=\max \left(\sum_{i=1}^{M} a_{i} k_{i}(x)-\sum_{j=1}^{N} a_{j} k_{j}(x)\right)
$$

з урахуванням множини обмежень $B_{i}^{\min } \leqslant k_{i}(x) \leqslant B_{i}^{\max }$ та попередньою нормалізацією частинних критеріїв.

\section{IV. Висновки}

1. Застосування комплексного підходу до вибору складу СУС дозволяе підвищити якість рішень за рахунок врахування взаємозв'язків та особливостей основних компонентів задачі: ОВ, ЗУС та ТП.

2. Для реалізації функціонально-технологічного узгодження ОВ і ЗУС як ключового етапу вибору раціонального складу СУС при комплексному підході запропонована нейро-фаззі модель, що дозволяє врахувати лінгвістичні та інші навизначеності та використати наявну базу емпіричних знань.

3. Для алгоритмізації та автоматизованого вибору ЗУС запропоновано узагальнену методику, що дозволяе практично реалізувати поетапний вибір раціонального складу СУС.

\section{Список використаних джерел}

1. Олійник В.В. Концептуальний підхід до визначення складу СУС як задачі прийняття рішень в умовах лінгвістичної невизначеності / В.В. Олейник // Адаптивні системи автоматично- 
го управління: міжвід. наук.-тех. збірник. - Дніпропетровськ: ДНВП Системні технології. - 2008. - №13(33). - С.64-68.

2. Олійник B.В. Експериментальне дослідження нейро-фраззі моделі узгодження об'єктів виробництва і засобів упорядкування середовища / В.В. Олейник, Л.С. Ямпольський // Адаптивні системи автоматичного управління: міжвід. наук.-тех. збірник. Дніпропетровськ: ДНВП Системні технології. - 2010. - №17(37). - C.86-93.

3. Олейник B.B. Решение задачи рационального выбора наилучшей семантики в рамках семантически-согласованной среды в компьютерно-интегрированных производственных системах / В.В. Олейник, Л.С. Ямпольский, О.И. Лисовиченко // Адаптивні системи автоматичного управління: міжвід. наук.тех. збірник. - Дніпропетровськ: ДНВП Системні технології. 2006. - №9(29). - С. 93-101.

Отримано 05.09.2014 p. 